\title{
Alternative Assessment Tools for the Writing Skill Development of EFL Learners
}

\author{
Paola Vanessa Navarrete Cuesta, Mg \\ Docente de la Pontifica Universidad Católica \\ del Ecuador sede Ambato, Ecuador \\ Jazmina Ivonne Mena Mayorga, Mg \\ Yajaira Natali Padilla Padilla, $M g$ \\ Angel Paul Obregon Mayorga, $M$ \\ Docente de la Escuela Superior Politécnica de Chimborazo, \\ Centro de Idiomas, Ecuador
}

Doi:10.19044/esj.2019.v15n7p177～ＵRL:http://dx.doi.org/10.19044/esj.2019.v15n7p177

\begin{abstract}
This paper focuses on improving the writing skill through the application of strategies based on alternative assessment to EFL students in a private university of Ecuador. This inquiry analyses how the application of alternative assessment tools affect the development of the writing skill of EFL learners. The target population of this study was 23 students who take English lessons at the first level. This research used the quasi-experimental design with an experimental group only. The instruments used to collect data were a pretest and a posttest applied to the experimental group. The results obtained in both tests were compared and analyzed using the percentage system represented in charts. After the data analysis, it was concluded that alternative assessment positively affects the development of the writing skill of EFL learners. Thus, they have all enhanced their writing competence. Therefore, this study concludes that after the application of alternative assessment tools, students discovered that the writing process became more meaningful. Based on the findings, the researchers recommend the use of different alternative assessment tools in order to enrich the writing skill.
\end{abstract}

Keywords: Alternative assessment, Writing skill, EFL learners

\section{Introduction}

Assessment is considered one of the most relevant aspects in education because it leads the decisions made on the students learning process. Lorna, Steven, (2006) define assessment as a process which uses diverse tools created to ratify the knowledge gained by students. Alternative assessment also called 
authentic assessment offers a wide variety of options that are real-world tasks for students to develop their writing skill and also their critical thinking. Authentic tasks, therefore, involve students in problems that are similar to those encountered in real life situations. On the other hand, according to ( Dietel, Herman, and Knuth 1991), a consequence of using traditional assessment is that students tend to memorize facts with little opportunity to practice higher-order thinking skills. Thus, wrongly selected assessment strategies such as traditional paper tests are disadvantageous to students and this affects them negatively.

While a traditional test is aimed to take a snapshot of what the student knows, the authentic assessment task encompasses students in activities that actually make learning more meaningful and builds on the student's present knowledge and skills. As a student is engaged in assessment tasks provided by the teacher, both learning and assessment will occur.

(Berry, 2008) states that the most common alternative assessment tools are observations, experiments, journals, portfolios, exhibitions, oral presentations, interviews and projects. Alternative assessment tasks require learners to produce or demonstrate their own learning with product-oriented assessment.

\section{Authentic Assessment Strategies}

\section{Self-assessment}

Self-assessment draws its theoretical justification from a number of recognized principles from second language acquisition. The principle of autonomy is highlighted as a fundamental stone in the students' success. This engages students in their own formative assessment process. They compare their work using established criteria provided by the teacher and work on their own improvements (Brown, 2004).

\section{Peer-Assessment}

Brown and Hudson (1998) agree that peer-assessment offers some benefits such as direct involvement of students in their own learning, the encouragement of autonomy, and increased motivation. Many people go through a program of education from kindergarten up to a graduate degree and never appreciate the importance of collaborative work. Thus, it is essential to work on activities where students learn to share knowledge but also have the ability to judge and criticize the work of their classmates.

\section{Types of Self and Peer-assessment}

It is necessary to distinguish between different types of self and peer assessment and apply them accordingly (Brown, 2004). 
- Direct Assessment of Performance: Students observe themselves in oral or written production. The evaluation takes place immediately or soon after the performance. After students work on an oral presentation, the peer fills out a check list which rates students' performance.

- Students Self-generated Tests: These are not usually classified firmly as self or peer-assessment. It is the method of involving students in the process of building tests themselves. The traditional view of what a test is would never permit students to engage in tests structure. However, studentsgenerated tests can be productive and intrinsically motivating.

\section{Portfolios}

Arter and Spandel (1991) illustrate that portfolios are a focused collection of students' effort alongside their learning process. The collection ought to include learners' contributions in selecting contents, the criteria for collection, the criteria for judging merit, and indicators of student personalreflection.

Brown (2004) mentions that the material portfolios might include:

- Essays and compositions in draft and final forms;

- Reports and project outline;

- Poetry and creative prose;

- Artwork, photos, newspaper or magazine clippings;

- Audio and/ or video recordings of presentations, demonstrations, etc.;

- Journals, diaries, and other personal reflections;

- Test, test scores, and other written homework exercise;

- Notes on lectures;

- Self and peer-assessments - comments, evaluations, and checklists. Gottlieb (1995) cited in Brown (2004) recommended a developing scheme for considering the determination of portfolios, using the acronym CRADLE to plan six potential features of portfolio:

- Collecting

- Reflecting

- Assessing

- Documenting

- Linking

- Evaluating

Brown (2004) relates the acronym as collection, while portfolios are seen as students' identity. The freedom of students to select what to collect should be appreciated, but the objectives of the portfolio must be clear. Reflective practice through journals and assessment check-list is necessary for the success of a portfolio. Teachers and students should take the role of assessing the portfolio seriously as they evaluate the progress over time. The 
portfolio is an important document which demonstrates student's achievements. The portfolio can also serve as a link between students, teachers, community, peers, and authorities created with pride which displays student's uniqueness. Finally, evaluating a portfolio can be time-consuming, but it is a fulfilling process of generating knowledge.

Portfolios give numbers of potential benefits when creating them:

- Foster intrinsic motivation, responsibility, and ownership;

- Promotes student-teacher interaction with the teacher as a facilitator;

- Individualize learning and celebrate the uniqueness of each student;

- Provide tangible evidence of a student's work;

- Facilitates critical thinking, self-assessment, and revision processes;

- Offers opportunities for collaborative work with peers;

- Permit assessment of multiple dimensions of language learning.

\section{Learning Journals}

According to Hamayan (1995), common entrances that students make in their journals can provide teachers a vision that not only shows students' language ability, but their awareness of the learning process. The author emphasizes the importance of journals in the classroom and how it influences the learning process.

On the other hand, Brown's (2004) study confirms that fifty years ago, journals had no place in the second language classroom. The concept of free writing was confined almost exclusively in developing essays on assigned topics. Today, journals occupy an important role that allows students develop a self-reflection and take charge of their own destiny.

A journal is a register of students thoughts, feeling, reactions, assessment, ideas, and progress towards goals. It is usually written with little attention to structure, form, and correctness. Students can articulate their thought when they are judged later by the teacher. Sometimes, journals are confused sets of language with no particular point, purpose or audience. Fortunately, models of journeys used in education have tightened up to give this type of journals a focus. A number of overlapping categories have emerged in journal writing such as:

- Language- learning logs

- Grammar journals

- Responses to reading

- Strategies based learning logs

- Self-assessment reflections

- Diaries or attitudes, feelings, and other affective factors

- Acculturations logs 


\section{Concept Map}

Concept maps offer learners the chance to reflect thoughtfully. They can aid as a meta-learning strategy that helps learners to learn. It can also support learners to organize and comprehend more evidently new information to be learned. By a concept map, learners connect their new knowledge with their own existing knowledge.

\section{Projects}

Berry (2008) claims that projects offer useful data about learners' understanding, awareness of specific learning areas, and skills to apply in particular studies. This also includes the capabilities to communicate subjectspecific data clearly. Most projects need learners to assume an investigation process in which they work in groups or separately to select a topic, design a data collection process, examine and organize the data collected, and then display the results.

\section{Exhibitions}

Exhibits are the product of a topic studied in depth. Producing the exhibit demands effort and time as well as deep understanding of the subject matter. Exhibitions provide both teachers and students a chance to gain a better view of what students are learning and accomplishing (Klenowski, 2000).

\section{Interview}

According to Brown (2004), an interview is proposed to represent a context in which the teacher converses with a student for a designated assessment determination. Interviews might have one or numerous possible aims in which the teacher:

- Assesses the students' oral production,

- Ascertains a student's needs before designing a course or curriculum,

- Seeks to discover a student`s learning styles and preferences,

- Asks a student to assess his or her own performance,

- Requests or evaluate a course.

Moreover, to keep the all-important reliability factor, interview questions must be built carefully to elicit focus as a reply. As there are a lot of objectives, it is difficult to establish the principles. Nevertheless, the following guidelines may help efficiently:

- Offer an initial atmosphere and anxiety- lowering warm up;

- Begin with relatively simple questions;

- Continue with level-check and probe question, but adapt to the interviewee as needed;

- Frame questions simply and directly; 
- Focus on only one factor for each question. Do not combine several objectives in one question;

- Be prepared to repeat or reframe questions that are not understood;

- Wind down with friendly and reassuring closing comments.

\section{Writing Skill}

Spratt (2005) claims that one of the reasons why students find the writing skill quite complicated is because writing is a productive skill. Wendy Scott and Lisbeth Ytreberg (1991) claim that body language, tone of voice, eye contact, and some other characteristics of language cannot be present in writing. Hence, many students take a long time to domain the writing skill. In addition, correcting errors has been another reason for students to fail in their writing process. However, if professors use meaningful authentic tasks to develop writing, then errors could be improved without making students feel embarrassed for their mistakes.

This research contributes to the teaching and learning process, improving the writing skill proficiency of EFL learners through the practice of authentic writing tasks. Alternative assessment also provides teachers and learners the opportunity to focus their attention on communication rather than on right or wrong answers.

\section{Methodology}

The research is of qualitative-quantitative design. This research is based on the comparison of pre and post results on an experimental group after a period of eight weeks of experimentation. It was carried out with students of the first level of a private university in Ambato-Ecuador, with similar characteristics such as the level of knowledge, the age, and timing of class. At the end of the period of application of the intervention plan, the results were compared.

The level of the research was quasi-experimental with only experimental group that was subjected to the previous and subsequent examination. The study was carried out in the institution where the researchers work with a pre-established study group. The available population under the study was 23 students.

The type of research was bibliographic because the researchers did a bibliographical review on the subject. It was presented in the place of the facts during the completed investigative process and documentary because it argues the reason for the events.

It was sectional or transversal and correlational because of the relationship between the two variables; there is also a relation between authentic assessment and writing skill. In addition, assessment screens the results of the learning process and judges the development of the writing skill 
in students. The independent variable has to do with alternative assessment, and the dependent variable has to do with writing skill.

Furthermore, it has two principles: the Principle of exhaustiveness (the system of categories must contemplate all the alternatives of variation that the variable has) and the Principle of exclusivity (the categories must be mutually exclusive; the same element cannot be placed in two categories at the same time).

The pre-test and the post-test were used as part of the intervention. Firstly, a test was applied to the experimental group. Subsequently, the intervention was carried out and at the end of the application the same instrument was applied in a post-test manner to determine the level of relationship between the variables and the results of the intervention.

The intervention intended to change the existing reality through the application of authentic assessment tools to develop the writing skills in EFL learners.

\section{Results}

Below are the data analysis and comparison of the pre and post-tests findings.

\section{Analysis of Pretest Results}

Table 1.

Question 1: Find the correct vocabulary word according to the definition given.

\begin{tabular}{ccccc}
\hline \multicolumn{5}{c}{ QUESTION 1 } \\
\hline Score & Frequency & Percentage & $\begin{array}{c}\text { Valid } \\
\text { percentage }\end{array}$ & $\begin{array}{c}\text { Accumulated } \\
\text { percentage }\end{array}$ \\
20 & 4 & 17.4 & 17.4 & 17.4 \\
60 & 5 & 21.7 & 21.7 & 39.1 \\
80 & 8 & 34.8 & 34.8 & 73.9 \\
100 & 6 & 26.1 & 26.1 & 100.0 \\
Total & 23 & 100.0 & 100.0 & \\
\hline
\end{tabular}

Table 2

Question 2: Complete the gaps with the appropriate part of speech.

\begin{tabular}{|c|c|c|c|c|c|}
\hline \multicolumn{6}{|c|}{ QUESTION 2} \\
\hline & & Frequency & Percentage & $\begin{array}{c}\text { Valid } \\
\text { percentage }\end{array}$ & $\begin{array}{l}\text { Accumulated } \\
\text { percentage }\end{array}$ \\
\hline \multirow[t]{5}{*}{ Valid } & 20 & 2 & 8.7 & 8.7 & 8.7 \\
\hline & 60 & 7 & 30.4 & 30.4 & 39.1 \\
\hline & 80 & 5 & 21.7 & 21.7 & 60.9 \\
\hline & 100 & 9 & 39.1 & 39.1 & 100.0 \\
\hline & Total & 23 & 100.0 & 100.0 & \\
\hline
\end{tabular}


Table 3

Question 3: Read the text and find specific information.

\begin{tabular}{|c|c|c|c|c|c|}
\hline \multicolumn{6}{|c|}{ QUESTION 3} \\
\hline & & Frequency & Percentage & $\begin{array}{c}\text { Valid } \\
\text { percentage }\end{array}$ & $\begin{array}{l}\text { Accumulated } \\
\text { percentage }\end{array}$ \\
\hline \multirow[t]{5}{*}{ Valid } & 20 & 8 & 34.8 & 34.8 & 34.8 \\
\hline & 60 & 8 & 34.8 & 34.8 & 69.6 \\
\hline & 80 & 5 & 21.7 & 21.7 & 91.3 \\
\hline & 100 & 2 & 8.7 & 8.7 & 100.0 \\
\hline & Total & 23 & 100.0 & 100.0 & \\
\hline
\end{tabular}

\section{Discussion of the Pre-test Results}

According to the results obtained in the tables above, from the application of the pre-test, it is observed that in question 1 of a total of 23 students, $17.4 \%$ reached a percentage rating of $20 \%, 21.7 \%$ reached a percentage score of $60 \%$, 34.8 reached a percentage of $80 \%$, while for $26.1 \%$ it is in an expected or satisfactory range (100\%). In question 2, it is analyzed that $8.7 \%$ reached a minimum of $20 \%, 30.4$ reached a percentage rating of $60 \%, 21.7 \%$ exceeded the $80 \%$ rating, while only $39.1 \%$ reached a $100 \%$ rating. With regards to question 3 , it is observed that there are two equal percentages of $34 \%$, ranking in a range of 20 to $60 \%$ of the qualification according to the applied test. In the same way, it is obtained that $21.7 \%$ reached a qualification of $80 \%$ and a small group of students of $8.7 \%$ are rated $100 \%$.

\section{Conclusion of the Pre-test Results}

After applying the test to measure the level of knowledge of the students, it is observed that there are percentages which are below an acceptable or satisfactory rating according to learning.

\section{Analysis of Post-test Results}

Table 4

Question 1: Find the correct vocabulary word according to the definition given

\begin{tabular}{crrrr}
\hline \multicolumn{4}{c}{ QUESTION 1 POST TEST } & \\
\hline & Frequency & Percentage & $\begin{array}{c}\text { Valid } \\
\text { percentage }\end{array}$ & $\begin{array}{c}\text { Accumulated } \\
\text { percentage }\end{array}$ \\
& & & & 26.1 \\
10 & 6 & 26.1 & 73.9 & 26.1 \\
Total & 17 & 73.9 & 100.0 & \\
\hline
\end{tabular}


Table 5

Question 2: Complete the gaps with the appropriate part of speech.

\begin{tabular}{llll}
\multicolumn{4}{c}{ QUESTION 2 POST TEST } \\
Frequency & Percentage & $\begin{array}{c}\text { Valid } \\
\text { percentage }\end{array}$ & $\begin{array}{c}\text { Accumulated } \\
\text { percentage }\end{array}$
\end{tabular}

\begin{tabular}{crrrr}
80 & 5 & 21.7 & 21.7 & 21.7 \\
100 & 18 & 78.3 & 78.3 & 100.0 \\
Total & 23 & 100.0 & 100.0 & \\
\hline
\end{tabular}

Table 6

Question 3: Read the text and find specific information.

\begin{tabular}{crrrr}
\hline \multicolumn{5}{c}{ QUESTION 3 POST TEST } \\
\hline & Frequency & Percentage & $\begin{array}{c}\text { Valid } \\
\text { percentage }\end{array}$ & $\begin{array}{c}\text { Accumulated } \\
\text { percentage }\end{array}$ \\
& & & 47.8 & 47.8 \\
80 & 11 & 47.8 & 52.2 & 100.0 \\
100 & 12 & 52.2 & 100.0 & \\
Total & 23 & 100.0 & &
\end{tabular}

\section{Discussion of the Post-test Results}

According to the data obtained from the question 1 post-test, it is observed that $26.1 \%$ reached a grade of $80 \%$, while $73.9 \%$ of the students are in an outstanding grade reaching $100 \%$.

In the question 2 post-test, it is found that $21.7 \%$ reached a score of $80 \%$, and $78.3 \%$ reached a score of $100 \%$, achieving satisfaction with respect to the acquired learning.

The question 3 posttest shows that $47.8 \%$ of the students obtained a percentage score of $80 \%$, while $52.2 \%$ achieve the $100 \%$ score.

\section{Conclusion of the Post- test Results}

According to the analyzed results of the post-test, it is observed that the students obtained acceptable or satisfactory percentages according to the evaluation done. This showed an accurate measure in students learning and knowledge.

\section{Comparison Between the Pretest and the Post-test}

Table 7

Paired Sample Statistics 


\section{Analysis}

From the data obtained, it is observed that there is a difference in the arithmetic means or averages between the pre and post-tests, and it was improved after applying the proposal. This is done with regards to the understanding of the English language.

Table 8

\begin{tabular}{cccc} 
& Test of Paired Samples & Media & Sig. (bilateral) \\
\hline Pair 1 & QUESTION 1 - QUESTION 1 & -1.043 & .000 \\
Pair 2 & POST TEST & & .000 \\
Pair 3 & $\begin{array}{c}\text { QUESTION 2 - QUESTION 2 } \\
\text { POST TEST }\end{array}$ & -.870 & .000 \\
& POST TEST
\end{tabular}

\section{Final Discussion}

There is a significant difference between the means of the tests (Pre and Post) applied to the students. Thus, it is concluded that the present proposal has a significant effect on the learning of English writing skill.

\section{Conclusion}

- The writing skill of the EFL students subjected to the experimentation with strategies based on alternative assessment increased considerably as it was shown in the corresponding data analysis of the posttest.

- The findings indicated that there was a significant difference in the arithmetic averages between the pre and post-tests. The data indicated that the grades which students obtained in the post-test outperformed the grades in the pre-test.

- Positive outcomes were found during the application of authentic assessment tools for the writing skill development. Components such as planning, authenticity, and innovation are a priority in the learning process. Consequently, most of the students have improved their proficiency in writing skill after being exposed to alternative tools.

- After the application of alternative assessment tools, teachers and students have found the writing process more interactive and meaningful. Therefore, there has been a feeling of improvement in the writing skill development.

\section{References:}

1. Arter Judith \& Vicki Spandel (2005). «Using Portfolios of Student Work in Instruction and Assessment». Educational Measurement: Issues and Practice 11, n. ${ }^{\circ}$ 1: 36-44. 
2. Berry, R. (2008). Assessment for learning. Retrieved from https://ebookcentral- proquest-com.pucesa.idm.oclc.org

3. Brown, H. \& Douglas (2006). Language Assessment: Principles and Classroom Practices. Nachdr. New York: Longman.

4. Brown James \& Thom Hudson (1998). «The Alternatives in Language Assessment». TESOL Quarterly 32, n. ${ }^{\circ}$ 4: 653.

5. Dietel, R. J., Herman, J. L., \& Knuth, R. A. (1991). What does research say about assessment? NCREL, Oak Brook. Retrieved from: https://es.scribd.com/document/150546037/What-DoesResearch-Say-About- Assessment.

6. Hamayan Else V (1995). «Approaches to Alternative Assessment». Annual Review of Applied Linguistics 15: 212.

7. Klenowski Val (2000) «Portfolios: Promoting Teaching». Assessment in Education: Principles, Policy \& Practice 7, n. ${ }^{\circ} 2: 215-$ 36.

8. Lorna, E. \& Steven, K. (2006). Chapter 5: Assessment of Learning Rethinking Classroom Assessment with Purpose in Mind. Western and Northern Canadian Protocol: British Columbia, Canada.

9. Spratt, M. (2005). Washback and the classroom: the implications for teaching and learning of studies of washback from exams. Language Teaching Research

10. Wendy Scott, A. \& Lisbeth Ytreberg, H. (1991). Teaching English to Children. New York: Neville Grant. 